\title{
Entre la vida buena y la buena vida Representaciones de la cultura en periódicos y revistas de circulación nacional'
}

Elkin Rubiano

Pontificia Universidad Javeriana-Universidad Externado de Colombia

Universidad Jorge Tadeo Lozano

elkinrubiano@yahoo.es

\section{Resumen}

El estudio de caso presentado hace un análisis de contenido de las páginas culturales de los periódicos EI Tiempo y EI Espectador, y las revistas Semana y Cambio, para mostrar qué construcción hace de "la cultura" el periodismo cultural.

\section{Palabras clave}

Cultura, páginas culturales, periodismo cultural.

\section{ABSTRACT}

The study of case presented makes an analysis of content of the cultural pages of the newspapers EI Tiempo and EI Espectador, and the magazines Semana and Cambio to show what construction does of "the culture" the cultural journalism.

\section{KEY WORDS}

Culture, cultural pages, cultural journalism.

1 El texto hace parte de la investigación La cultura encrucijada: Concepciones, representaciones y acciones de una noción escurridiza, para optar al título de maestría en comunicación de la Pontificia Universidad Javeriana. 


\section{Introducción}

$\mathrm{H}$ ay varios modos de entender la noción de cultura. Como "cultivo": un ideal cultural que debe ser perseguido según la valoración de los bienes culturales (legítimos vs. ilegítimos); como "acción": la posibilidad que tienen los actores sociales de renovar sus percepciones del mundo mediante la creación y el cambio; como "orden": la capacidad de la estructura social para mantener la regularidad del mundo mediante la preservación de una tradición y un patrimonio; como "estructuradora de la identidad", como "fuente de diversidad", como "recurso" económico y social, la cultura es un concepto de difícil aprehensión.

A pesar de tal dificultad no resulta extraño que, dependiendo de la empresa, se construya su concepto según los fines a alcanzar: las políticas culturales apelan hoy en día a la democracia y la diversidad, la economía de la cultura a la rentabilidad empresarial y el crecimiento económico de las naciones, la escuela a la preservación de la cultura y el cultivo de lo sancionado como culturalmente legítimo. Por esa misma vía, el propósito de este estudio es indagar cómo se construye ese concepto en las páginas culturales de los periódicos y revistas de circulación nacional: ¿Qué bienes simbólicos son divulgados en la prensa? ¿Qué se omite y a qué se le da visibilidad en las páginas culturales? Es decir, ¿¿cuál es la representación que los periódicos y revistas colombianas construyen sobre la cultura?

Aunque la prensa ha sido uno de los medios de comunicación más estudiados, gran parte del análisis se ha concentrado en algunas áreas: editorial, política, conflicto armado, seguridad y economía. No resulta extraño que los estudios se interesen por las zonas duras de la prensa ${ }^{2}$, especialmente en contextos como el nuestro. No obstante esa concentración, debe indicarse que los

2 Las zonas duras se apoyan en "un tipo de discurso informativo y argumentativo, más abstracto y estructural", mientras que las zonas blandas (deportes, espectáculos, policial) recurren a "un discurso más narrativo y casuístico, concreto y personalizado" (Ford, Martni y Mazzioti, 1996). estudios culturales han ido desplazando las preguntas sobre la prensa hacia las zonas blandas, en particular si se piensa en los estudios sobre los sectores populares y la llamada prensa sensacionalista. Los nombres de Sunkel y Fiske vienen a la memoria en casos como éstos. Sin embargo, y a pesar del interés creciente por lo popular, el mundo del espectáculo y la televisión, es muy poco lo que se ha dicho sobre la cultura en la prensa o, de modo más preciso, sobre lo que la prensa ha etiquetado como cultura: las "páginas culturales", propósito del presente estudio.

Salvo críticas hechas al periodismo cultural (Martín-Barbero, 1991; Moreno-Durán, 1993; Zaid, 2006) ${ }^{3}$ o indagaciones teóricas sobre el oficio y la misión del periodismo cultural en un sentido normativo (Rivera, 1995; Barei, 1999; Villa, 2000; Esteinou, 1998), es difícil encontrar investigaciones que se apoyen en la recolección de material empírico. Sobresale en ese campo desolado un interesante estudio de García Canclini (2000) en el que se señala que aunque el tema de la cultura tiene cada vez más cabida en los diarios mexicanos, esa "expansión de la cultura no ocurre del mismo modo en las distintas secciones de los periódicos" debido a los "diversos modos de organizar lo local, lo nacional y lo global en distintos campos culturales": lo global en espectáculos, economía e informática; lo nacional y lo local en la sección titulada "cultura", dedicada en gran parte a los bienes culturales de la "alta cultura". No obstante lo interesante de los resultados, resulta inquietante la utilización de las variables "alta cultura" y "cultura popular", después de que el autor ha teorizado sobre hibridaciones

3 Cabe hacer una distinción entre dos tipos de crítica: la docta y la culturalista. La primera crítica señala la falta de nivel cultural: "el diálogo cultural se hace redundante (...) responde a un patrón ya cansado: el coloquio entre entrevistado y presentador. $Y$ hablamos de coloquio por generosidad semántica" (Moreno-Duran, 1993) o "Los periodistas culturales no informan sobre lo que dijo el piano maravillosamente (..) Informan sobre los calcetines del pianista" (Zaid, 2006: 18). La segunda crítica señala la falta de diversidad cultural: "la visión banalizadora de la cultura para la cual lo único que es digerible por los estómagos posmodernos es lo fragmentario y leve, y que justifica la reducción a eso mismo de lo que en la cultura nos queda de diferencia y de diversidad" (Martín-Barbero, 1991: 29). 
(1990) y ha llamado a la reserva frente a las concepciones jerárquicas de la cultura (2004). Ahí la distancia entre teoría y categoría empírica hace cortocircuito.

Intentando evitar ese corto, en esta indagación se optó por diseñar unas categorías que en lugar de agrupar el bien cultural según el tipo de valoración social, lo agrupa según el circuito de circulación del bien cultural mediante las variables tipo, territorio y circuito promotor de las creaciones y producciones culturales.

\section{Captura y codificación de la información}

Para el análisis de contenido de las páginas culturales se seleccionaron los periódicos El Tiempo y El Espectador y las revistas Semana y Cambio, debido a que son publicaciones periódicas de circulación nacional de gran tiraje y gran visibilidad mediática. La unidad de análisis recoge el contenido de las páginas culturales correspondientes a las publicaciones del mes de julio de 2004 .

Aunque la muestra se compone de dos periódicos, debe indicarse que sólo El Tiempo es de publicación diaria; El Espectador es un periódico que pasó de diario a semanario en 2002. Presentemos el listado de los cinco periódicos con más lectores entre 1999 y 2002, para ubicar de mejor modo nuestra unidad de análisis en el Cuadro 5.

Si El Tiempo y El Espectador agrupan una gran cantidad de lectores, debe señalarse que para el caso que nos ocupa, la página de cultura y entretenimiento tiene gran acogida dentro de sus lectores habituales, pues en El Tiempo la consultan el $42.72 \%$ y en El Espectador el $39.63 \%$ (Datos EGM, 2004).
En cuanto a las revistas Semana y Cambio, la primera tiene el mayor porcentaje de lectores habituales de revistas $(8.44 \%)$, mientras que Cambio, aunque no se ubica en los primeros lugares (1.70\%), concentra con Semana los dos primeros de la inversión publicitaria en revistas (17.80\% y $9.20 \%$, respectivamente).

Los datos de las publicaciones periódicas analizadas se recogieron mediante las siguientes variables: tipo, territorio y circuito promotor de las creaciones y producciones culturales.

Con respecto al tipo de creación y producción cultural se utilizaron categorías según la modalidad de circulación con respecto a los públicos o consumidores:

- Circuito de circulación extendido (cine, literatura, música, escena y plástica)

- Circuito de circulación restringido (cine, literatura, música, escena y plástica)

- Producción popular ("folclorizado", circuito de circulación extendido -"popular-masivo"$\mathrm{y}$ arte popular)

Se utilizaron, igualmente, otras categorías con amplia dispersión dentro de la muestra: patrimonio/arquitectura/urbanismo, investigación, convocatorias, educativo, tecnologia y televisión.

Se optó por las categorías circuito de circulación extendido (CCE) y circuito de circulación restringido (CCR), al tener en cuenta la dificultad para clasificar las creaciones y producciones culturales en las categorías culto, popular o masivo. Debido a que las mixturas e hibridaciones, el kitsch y el pastiche imposibilitan la agrupación según el critério de la valoración del bien cultural, se diseñaron unas categorías analíticas ajustadas al volumen del consumo: creacio-

\begin{tabular}{|c|c|c|c|c|c|c|c|}
\hline \multicolumn{2}{|c|}{1999} & \multicolumn{2}{c|}{2000} & \multicolumn{2}{c|}{2001} & \multicolumn{2}{c|}{2002} \\
\hline El.Tiempo & $40.41 \%$ & El Tiempo & $42.70 \%$ & El Tiempo & $42.46 \%$ & El Tiempo & $34.10 \%$ \\
\hline El Colombiano & $11.25 \%$ & El Colombiano & $9.87 \%$ & El Heraldo & $11.69 \%$ & El Espectador & $19.64 \%$ \\
\hline El Espacio & $8.3 \%$ & El Heraldo & $8.87 \%$ & El Colombiano & $10.60 \%$ & El Espacio & $10.42 \%$ \\
\hline El Espectador & $7.08 \%$ & El Espacio & $8.32 \%$ & El Espacio & $8.11 \%$ & El Colombiano & $9.40 \%$ \\
\hline El País & $1.6 \%$ & El Espectador & $8.27 \%$ & El Espectador & $7.51 \%$ & Hoy & $7.68 \%$ \\
\hline
\end{tabular}

Cuadro 5: Lectores habituales de periódicos. Fuente: EGM tomada del Ministerio de Cultura (2003). 


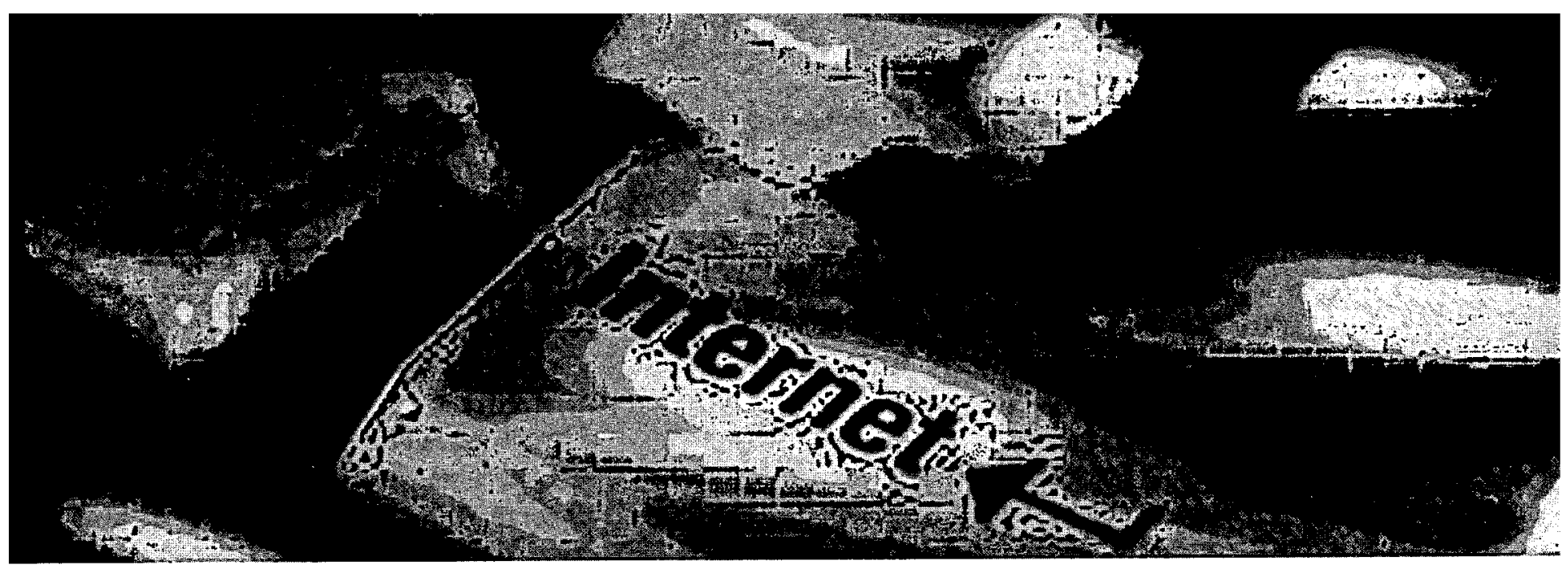

nes culturales para grandes públicos (CCE) y creaciones culturales para públicos minoritarios $y$ conocedores expertos (CCR). No obstante las reservas frente a las nociones de lo culto, lo popular y lo masivo, se prefirió conservar la categoría "popular" debido al planteamiento de una hipótesis de investigación comprobada en este estudio: las manifestaciones de la cultura popular son marginadas en el periodismo cultural escrito, salvo que estén legitimadas mediante las lógicas de los circuitos de producción, distribución y comercialización de bienes y contenidos simbólicos.

Para dejar en claro cómo se agruparon tales categorías señalemos algunos ejemplos: "Descanso de caminantes" de Adolfo Bioy Casares es literatura $C C R$, mientras que "¿Qué han hecho con mi país?” de Michael Moore es literatura $C C E$; el IV Festival de Danza Contemporánea es escénico CCR, mientras que "La pelota de letras" de Andrés López es escénico CCE; Arte de los Virreinatos de México y Nueva Granada en el Museo Nacional es plástico CCR, mientras que la exhibición del fotógrafo brasilero Sebastiao Salgado en el parque de la 93 es plástico CCE; el festival de "Cine Rosa" es cine $C C R$, mientras que "El día después de mañana" es cine $C C E$. En cuanto a la categoría popular: "Música brasileña en la Blaa" es popular-folclorizado, "Los Tigres del Norte recogen en sus canciones el sentir del pueblo mexicano" es popular-masivo (CCE) y el Primer Salón Nacional de Arte Popular en Colombia es arte popular.

- En cuanto al territorio de la creación y producción cultural, se utilizaron cuatro categorías:Internacional: agrupa las noticias referidas a producciones culturales hechas fuera de Colombia, subdivididas del siguiente modo:

- Circuito internacional: producciones extranjeras de las que da cuenta la prensa (la conmemoración del centenario de nacimiento de Pablo Neruda o la Bienal de São Paulo).

- Inter-local: producciones extranjeras que se presentan, estrenan o lanzan en Bogotá (el estreno de la película "La casa de los muertos" de Uwe Böll o el concierto de la Fania All Stars).

- Nacional: agrupa las noticias referidas a producciones culturales hechas en Colombia, subdivididas del siguiente modo:

- Circuito nacional: producciones colombianas que convocan a todo el territorio de las que da cuenta la prensa (convocatoria del Ministerio de Cultura para las tertulias literarias o la entrega de los premios de cultura a obra inédita, al patrimonio musical $\mathrm{y}$ a organizaciones culturales).

- Nación-internacional:producciones colombianas que se presentan, estrenan o lanzan fuera del país (la exposición de Fernando Botero en Tokio o la noticia sobre candidatos colombianos al Grammy Latino).

- Regional: agrupa las noticias referidas a producciones culturales hechas fuera de Bogotá pero dentro del territorio nacional, subdivididas del siguiente modo:

- Circuito regional: producciones culturales hechas en las regiones de las que da cuenta la 
prensa (la creación de la Sociedad de Amigos del Festival de Cine de Cartagena).

- Regional-local: producciones regionales que se presentan, estrenan o lanzan en Bogotá (bailarines del llano en el parque Simón Bolívar).

- Local: agrupa las noticias referidas a producciones culturales que circulan y se producen en Bogotá.

Finalmente, el circuito promotor de la creación y producción cultural se recogió en tres categorías:

- Empresarial: circuito cuya finalidad es la rentabilidad económica (industrias culturales o empresas culturales que buscan la maximización del beneficio monetario).

- Gubernamental: circuito promocionado por la administración pública nacional o distrital (financiación en cuanto a creación, producción, distribución, circulación y consumo de bienes y servicios culturales).

- Societal: circuito que no se ajusta a lo empresarial, aunque tenga contacto con él (la conmemoración del centenario de nacimiento de Pablo Neruda se sale del circuito comercial

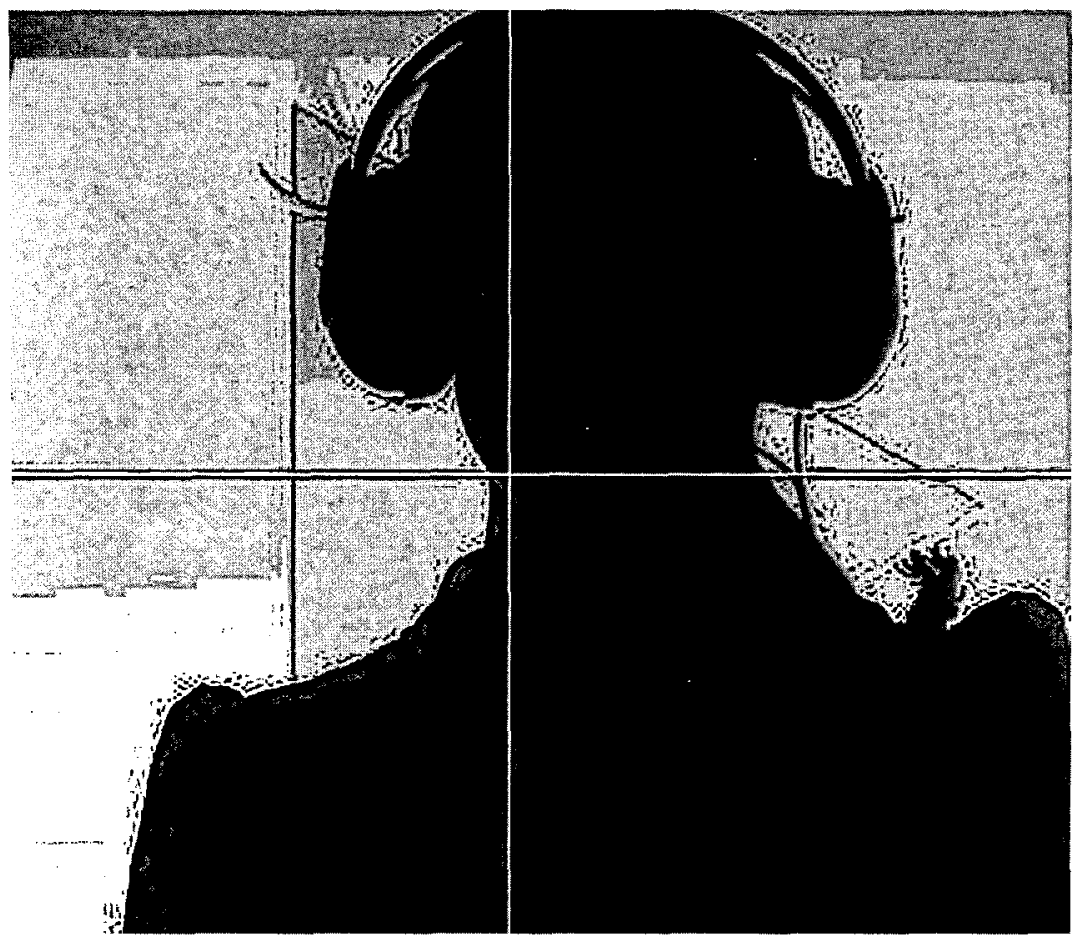

cuando en las escuelas se le rinde homenaje, se leen sus poemas, etc., aunque esté estrechamente ligada al circuito comercial: se reeditan sus obras, suben las ventas de sus libros, se lanzan biografías, etc.); pero tampoco se ajusta a lo gubernamental, aunque tenga contacto con él (el Encuentro de la Edición en España que propuso iniciativas como las tertulias literarias para aumentar los niveles de lectura convocan lo social sin necesidad de la intervención directa del mercado o el estado aunque uno y otro estén presentes: la ley del libro, la industria editorial, etc.).

\section{Las páginas culturales: entre la vida buena y la buena vida}

En este apartado se indica qué lugar es el que ocupa la página cultural en los periódicos y revistas. El lugar en que se ubica "la cultura" es un buen indicador para ir descubriendo la construcción que se hace de la cultura en los periódicos y revistas seleccionados.

En El Tiempo la página cultural está ubicada en la Sección 2 del periódico. Allí comparte espacio con otras secciones de modo invariable durante toda la semana: Deportes, Televisión (entrevistas con actores, reseñas sobre programas, parrilla), Monos (caricaturas), Horóscopo, Sociales (cocteles, etc.), Cine (cartelera), Vida de Hoy (tecnologias del yo) y Gente (perfil de alguien que haya sobresalido en cualquier área: deportes, artes, televisión, moda). Además de las invariantes, la Sección 2 de El Tiempo se especializa en un tema según el día de la semana: lunes (Lunes deportivo y Tecnología), miércoles (Salud y Vida), jueves (Viajar), viernes (Rock) y domingo (Panorama, Salud, Educación y Teléfono Rosa).

En El Espectador hay dos secciones que se relacionan con "la cultura" en un sentido amplio: Agenda y Arte y Gente. Este último es muy variado. Su página principal no tiene un contenido temático claramente definido. En la muestra de cinco ejemplares se encuentran los siguientes temas: pintura (un artista colombiano), dietas para adelgazar (la falacia de las dietas), poesía (el aniversario de la muerte de María Mercedes $\mathrm{Ca}^{-}$ rranza), diseño de moda (el diseño artesanal de 
Pepa Pombo) y vinos (una vendimia en Villa de Leiva). En las páginas interiores se encuentran las siguientes subsecciones: Vida Moderna (tecnologias del yo), Cocina (recetario), Medios (radio, televisión, ranking), Sociales (cocteles, etc.), Destinos (turismo), Crucigrama, Alto Turmequé (chismes del mundo light y la vida política) y Plantas y Tarot (horóscopo).

Igualmente la sección Agenda muestra un registro amplio en cuanto a cubrimiento de eventos culturales: Cine, conciertos, exposiciones, etc. En Agenda hay varias subsecciones: Cultura -la unidad de nuestro análisis-, Goce de rumba (recomendaciones para la diversión: bares, restaurantes, etc.), Cartelera de cine (aparte de la cartelera hay un página dedicada a algún director, actor o película), Publicidad y Mercadeo (marcas), Espec- tagrama (crucigrama que pone a prueba el "conocimiento cultural" - nombres de actores, escritores, cantantes, personajes de películas, etc.) $-y$, finalmente, una sección llamada Niños, dedicada exclusivamente a actividades culturales infantiles.

A diferencia de los periódicos, en las revistas Semana y Cambio "la cultura" tiene una sección aparte con una estructura bastante similar: una primera página que se extiende en un tema específico y luego, invariäblemente, música, cine y libros, $y$ algunas veces arte, televisión y entretenimiento, entre otros temas ocasionales. Pero, al igual que en los periódicos, la sección Cultura de las revistas se encuentra en medio de las secciones Gente, Vida Moderna y Deportes en Sema$n a, \mathrm{y}$ Tendencias, Sexo, Placer y A Flor de Piel en Cambio.

\begin{tabular}{|l|c|c|c|c|c|c|c|}
\hline EDAD & 12 a 19 & 20 a 24 & 25 a 34 & 35 a 44 & 45 a 54 & 55 a 64 & 65 a 69 \\
\hline E1 Tiempo & $12.95 \%$ & $10.78 \%$ & $21.98 \%$ & $19.45 \%$ & $16.91 \%$ & $12.68 \%$ & $6.13 \%$ \\
\hline E1 Espectador & $22.09 \%$ & $13.37 \%$ & $18.02 \%$ & $17.44 \%$ & $11.04 \%$ & $12.79 \%$ & $5.23 \%$ \\
\hline Semana & $16.29 \%$ & $11.73 \%$ & $22.90 \%$ & $21.78 \%$ & $15.08 \%$ & $7.26 \%$ & $5.02 \%$ \\
\hline Cambio & $9.25 \%$ & $12.96 \%$ & $22.22 \%$ & $22.22 \%$ & $18.51 \%$ & $11.11 \%$ & $3.7 \%$ \\
\hline
\end{tabular}

Cuadro 6: Lectores de periódicos y revistas distribuidos por edad. Fuente: EGM (2004)

\begin{tabular}{|l|l|l|l|l|}
\hline ESCOLARIDAD & E1 Tiempo & E1 Espectador & Semana & Cambio \\
\hline Doctorado & $1.26 \%$ & $2.32 \%$ & $3.35 \%$ & $1.85 \%$ \\
\hline Maestría/especialización & $13.10 \%$ & $9.88 \%$ & $13.96 \%$ & $20.37 \%$ \\
\hline Universidad completa & $34.24 \%$ & $2.32 \%$ & $29.05 \%$ & $27.77 \%$ \\
\hline Universidad incompleta & $14.37 \%$ & $15.11 \%$ & $19.55 \%$ & $29.62 \%$ \\
\hline Técnico completo & $8.45 \%$ & $4.65 \%$ & $7.26 \%$ & $7.40 \%$ \\
\hline Técnico incompleto & $1.47 \%$ & $1.74 \%$ & $2.79 \%$ & $0 \%$ \\
\hline Bachillerato completo & $8.24 \%$ & $13.37 \%$ & $6.14 \%$ & $5.55 \%$ \\
\hline Bachillerato incompleto & $14.37 \%$ & $23.83 \%$ & $13.96 \%$ & $5.55 \%$ \\
\hline Primaria completa & $3.38 \%$ & $4.65 \%$ & $2.79 \%$ & $1.85 \%$ \\
\hline $\begin{array}{l}\text { Primaria incompleta/sin } \\
\text { estudios }\end{array}$ & $1.05 \%$ & $1.16 \%$ & $1.11 \%$ & $0 \%$ \\
\hline
\end{tabular}

Cuadro 7: Lectores de periódicos y revistas distribuidos por grado de escolaridad. Fuente: EGM (2004).

En el caso de los periódicos hay una mayor variedad temática. Tanto en la Sección 2 de El Tiempo como en Agenda y Arte y Gente de El Espectador, su amplio registro temático se debe a la diversidad de demandas de un público más fraccionado por estratificación social, ocupación, edad y grado de escolaridad, a diferencia de las revistas cuyo público lector tiende a ser más homogéneo.

Teniendo en cuenta la unidad de análisis y sus características generales, hay que anotar que en la llamada "prensa seria", la racional e iluminista que apela la objetividad con el uso 
de los datos y las cifras - "son los hèchos los que hablan", afirma el discurso abstracto-, es decir, en aquella prensa que discusivamente se legitima mediante una "ideología de la objetividad" (Sunkel, 1985 y 2004), "la cultura" aparece en medio de las secciones en el que el discurso objetivo y abstracto tiene licencia para ponerse en suspensión (Alto Turmequé, Teléfono Rosa, Sociales, Horóscopo), pero en el que el discurso objetivo y abstracto -que apela a valores universales construyendo sujetos creyentes, a juicio de Fiske- está autorizado para promocionar la "vida buena" (Vida Moderna, Salud y Vida) y la "buena vida" (Destinos, Cocina, Sexo, Placer, A Flor de Piel).

Ubicada en las llamadas zonas blandas de la prensa, no resulta extraño que las páginas culturales, apoyadas en la seriedad de su discurso, no sean ajenas al decálogo de la "vida buena" y al recetario de la "buena vida”, como se verá en el siguiente apartado.

\section{El periodismo cultural o el oficio de divulgar cositas}

El análisis dẻ contenido de las páginas culturales resulta útil para descubrir, por un lado, qué tipo de agenda informativa construye la prensa en cuestiones culturales y, por el otro, qué concepto de cultura es el que construye el discurso en tales páginas.

Llama la atención, en primer lugar, que los bienes culturales se concentran en el circuito de circulación restringido (CCR) y el circuito de circulación extendido (CCE), dejando de lado otras manifestaciones culturales como la popular, completamente nula en ambas revistas y prácticamente inexistente en el caso de El Tiempo (El Espectador marca una diferencia al respecto). En segundo lugar, el circuito promotor más visible tanto en los periódicos como en las revistas es el empresarial: El Tiempo (54.5\%), El Espectador (55,5\%), Semana (87.5\%) y Cambio (86.3\%). Ver Cuadro 8 y 9.

La estrecha relación entre CCE, CCR y el circuito empresarial se entiende analizando los datos en detalle: Aunque hay cinco categorías para agrupar los bienes culturales del CCE y el $\mathrm{CCR}$, la información se aglutina básicamente en tres: cine, música y literatura, sectores estratégicos del crecimiento y concentración económica de las industrias culturales, tanto para públicos mayoritarios (top 20 y best sellers) como para conocedores expertos (música o literatura especializadas cuya cadena productiva, igualmente, se concentra en las majors). De manera contextual debe tenerse en cuenta, que como recurso económico muchos informes indican que la cultura es uno de los sectores claves en las economías desarrolladas y que en las dos últimas décadas el comercio global de bienes y servicios culturales se ha cuadruplicado. Las páginas culturales no son; consecuentemente, ajenas a este proceso.

En este caso, tanto los periódicos como las revistas son una vitrina promocional del mercado de la cultura, especialmente con los listados de los libros más vendidos y las reseñas sobre lanzámientos y estrenos discográficos y cinematográfi$\cos$. Vitrina promocional más que ejercicio crítico, el periodismo cultural muestra un talante de puro divulgador cultural, más acentuado en el caso de los periódicos debido a su variado registro informativo, abundante información de notas breves (El Tiempo, 55.7\%, El Espectador, 47.2\%) y mayor porcentaje de notas sin autor. Aunque, claro está, las revistas no se alejan de ello aunque muestren otro estilo divulgativo: debiendo ofertar a un tipo lector más homogéneo tiende a concentrarse en determinados bienes culturales con sus respectivos comentaristas de catálogo que, difícilmente, se salen del guión establecido por el mercado de la cultura: se comenta lo que se vende.

Siendo así, las páginas culturales de periódicos y revistas convierten en decálogo y receta el universo de bienes simbólicos del mercado cultural. Antes que taste makers, oficio tradicional del crítico de arte o literatura, los comentaristas de las páginas culturales parecen taste workers de catálogo cuyo estilo resulta conforme con la erudición de contracarátula:

Un asesino en serie ronda las calles de Boston y la única pista para descubrirlo es la lectura de La divina comedia. Esta historia ha vendido más de un millón de copias. (El club 


\begin{tabular}{|l|c|c|c|c|}
\hline $\begin{array}{l}\text { Tipo de producción } \\
\text { cultural (detallado) }\end{array}$ & EL TIEMPO & EL ESPECTADOR & SEMANA & CAMBIO \\
\hline Cine CCE & $11,4 \%$ & $0 \%$ & $20.8 \%$ & $22.7 \%$ \\
\hline Literatura CCE & $8,2 \%$ & $16.7 \%$ & $8.3 \%$ & $4.5 \%$ \\
\hline Música CCE & $10,8 \%$ & $5.6 \%$ & $4.2 \%$ & $13.6 \%$ \\
\hline Escénico CCE & $3,2 \%$ & $0 \%$ & $0 \%$ & $0 \%$ \\
\hline Plástica CCE & $1,3 \%$ & $0 \%$ & $0 \%$ & $4.5 \%$ \\
\hline Cine CCR & $5,7 \%$ & $0 \%$ & $0 \%$ & $0 \%$ \\
\hline Literatura CCR & $12,7 \%$ & $5.6 \%$ & $16.7 \%$ & $18.2 \%$ \\
\hline Música CCR & $7,0 \%$ & $11.1 \%$ & $20 \%$ & $18.2 \%$ \\
\hline Escénico CCR & $2,5 \%$ & $8.3 \%$ & $0 \%$ & $0 \%$ \\
\hline Plástica CCR & $25,3 \%$ & $22.2 \%$ & $4.2 \%$ & $4.5 \%$ \\
\hline Popular-masivo & $1,3 \%$ & $0 \%$ & $0 \%$ & $0 \%$ \\
\hline Popular-folclorizado & $1,3 \%$ & $11.1 \%$ & $0 \%$ & $0 \%$ \\
\hline Arte popular & $0 \%$ & $2.8 \%$ & $0 \%$ & $0 \%$ \\
\hline Patrim/arq/urba & $1.3 \%$ & $0 \%$ & $12.5 \%$ & $0 \%$ \\
\hline Televisión & $0 \%$ & $0 \%$ & $8.3 \%$ & $4.5 \%$ \\
\hline Investigación & $0 \%$ & $0 \%$ & $4.2 \%$ & $9.5 \%$ \\
\hline Tecnología & $0.6 \%$ & $2.8 \%$ & $0 \%$ & $0 \%$ \\
\hline Educativo & $7.0 \%$ & $11.1 \%$ & $0 \%$ & $0 \%$ \\
\hline Convocatorias & $0.6 \%$ & $2.8 \%$ & $0 \%$ & $0 \%$ \\
\hline C & & & \\
\hline
\end{tabular}

Cuadro 8: Tipo de producción cultural (detallado)

\begin{tabular}{|l|c|c|c|c|}
\hline $\begin{array}{l}\text { Tipo de producción } \\
\text { cultural (agrupado) }\end{array}$ & EL TIEMPO & EL ESPECTADOR & SEMANA & CAMBIO \\
\hline CCE & $34.9 \%$ & $22.3 \%$ & $33.3 \%$ & $45.3 \%$ \\
\hline CCR & $53.2 \%$ & $47.2 \%$ & $40.9 \%$ & $40.9 \%$ \\
\hline Popular & $2.6 \%$ & $13.9 \%$ & $0 \%$ & $0 \%$ \\
\hline Otros & $9.5 \%$ & $16.7 \%$ & $25 \%$ & $14 \%$ \\
\hline
\end{tabular}

Cuadro 9: Tipo de producción cultural (agrupado)

de los poetas detectives. El club Dante, nuevo best seller policiaco, El Tiempo, 31-07-04)

Los informantes puede llegar a ser un espejo en el que de manera velada nos podemos mirar con un poco de vergüenza por la crudeza de su planteamiento, que renueva la importancia del destino al estilo de la tragedia griega ("Los informantes olvidados. Esta semana se lanzó la última novela de Vásquez", El Espectador, 24 al 30-07-04).
"El empaque no importa, y mucho menos la manera como se lo nombre, porque el geniecillo de Minneapolis ha regresado. Y lo ha hecho nuevamente bajo el nombre de Prince, después de privar al mundo entero de una manera lógica de llamarlo". ("El símbolo. El nuevo Prince, el Prince de siempre, regresa con aires conserviva dores", Cambio, 28/06 al 5/07 de 2004).

"Lo mejor de las nuevas películas de $E l$ hombre araña, lo que las acerca a la categoría 
del Batman de Tim Burton o del Superman de Richard Donner, es que no pierden de vista nunca el espíritu de las tiras cómicas creadas por Stan Lee y Steve Ditko, qùe se toman en serio los conflictos entre sus personajes y no olvidan que la condición del superhéroe de su protagonista es, sobre todo, una maldición sin salida". ("El hombre araña 2", Semana, 12 al 19-07-04).

Elanálisis de contenido
de las páginas culturales
resulta útil para describir,
por un lado, qué tipo de agenda
informativa construye la prensa
en cuestiones culturales y,
por otro, qué concepto de
cultura es el que construye el
discurso en tales páginas.

En casos representativos como éstos resulta evidente el talante puramente divulgativo del periodismo cultural: objeto más que práctica, la cultura se convierte, por un lado, en algo que el mercado pone a circular y el periodismo cultural, por el otro, en el eficiente informador de las cositas de la cultura: el evento, el escenario, la butaca y el ticket.

\section{La representación de la cultura en clave internacional y empresarial}

Si en las páginas culturales hay una estrecha relación entre mercado de la cultura e información cultural, resulta comprensible que la divulgación de las creaciones y producciones culturales internacionales ocupen gran espacio: $\mathrm{El}$ Tiempo 50.7\%, El Espectador 33.4\%, Semana 54.2\% y Cambio 59.1\%. Aquí la hegemonía de los circuitos culturales de circulación internacional muestra su lógica de funcionamiento. La industria cultural audiovisual, editorial y musical ocupa el primer lugar no sólo en el "mundo real" sino también en el "mundo de las representaciones mediáticas", tanto en el circuito internacional -noticias culturales fuera de Colombia-, como en el circuito local -producciones extranjeras que se presentan, estrenan o lanzan en Bogotá-.

No teniendo gran participación en las industrias culturales, el mayor porcentaje de la totalidad del circuito local de producción y circulación cultural que tiene espacio en las páginas culturales queda reservado al ámbito de la plástica $(40.2 \%$, dividido entre galerías y museos) y, correlativamente, la mayor participación porcentual sobre la totalidad de la producción y circulación cultural nacional con proyección internacional, queda reservada al ámbito del CCR que no convoca a grandes públicos: plástica $25 \%$, literatura CCR $15 \%$, escénico CCR $5 \%$ y música CCR 5\%, haciendo la salvedad que en música $\mathrm{CCE}$ hay una participación del $25 \%$, pero en este caso debe aclararse que si bien parte del contenido simbólico está en la creación nacional (cantantes, músicos, compositores), la totalidad del negocio está en la producción transnacional de las majors, propietarias de los derechos patrimoniales del bien cultural.

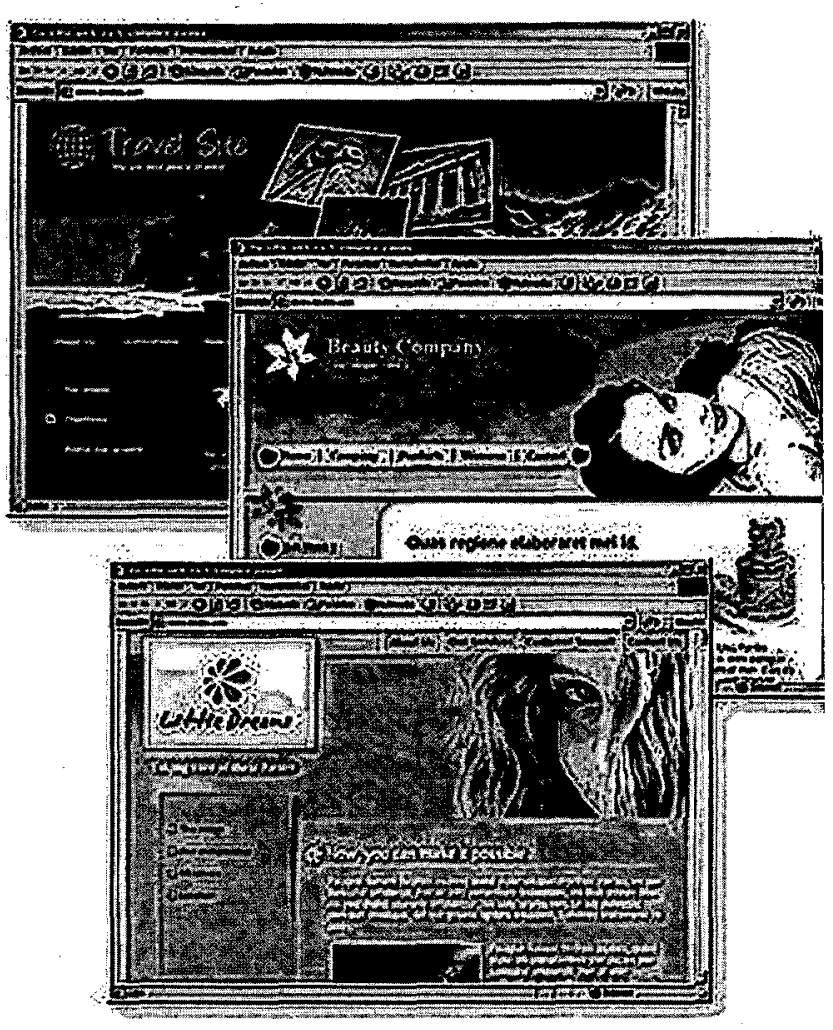




\begin{tabular}{|l|c|c|c|c|}
\hline $\begin{array}{l}\text { Territorio de la } \\
\text { producción (detallado) }\end{array}$ & EL TIEMPO & EL ESPECTADOR & SEMANA & CAMBIO \\
\hline Circuito-internacional & $24.1 \%$ & $5.6 \%$ & $0 \%$ & $9.1 \%$ \\
\hline Inter-local & $26.6 \%$ & $27.8 \%$ & $54.2 \%$ & $50 \%$ \\
\hline Circuito-nacional & $6.3 \%$ & $13.9 \%$ & $8.3 \%$ & $4.5 \%$ \\
\hline Nación-internacional & $10.8 \%$ & $0 \%$ & $8.3 \%$ & $4.5 \%$ \\
\hline Circuito-regional & $2.5 \%$ & $2.8 \%$ & $8.3 \%$ & $0 \%$ \\
\hline Inter-región & $0 \%$ & $0 \%$ & $0 \%$ & $0 \%$ \\
\hline Local & $27.8 \%$ & $44.4 \%$ & $20.8 \%$ & $31.8 \%$ \\
\hline
\end{tabular}

Cuadro 10: Territorio de la producción cultural (detallado).

\begin{tabular}{|l|c|c|c|c|}
\hline $\begin{array}{l}\text { Territorio de la } \\
\text { producción (agrupado) }\end{array}$ & EL TIEMPO & EL ESPECTADOR & SEMANA & CAMBIO \\
\hline Internacional & $50.7 \%$ & $33.4 \%$ & $54.2 \%$ & $59.1 \%$ \\
\hline Nacional & $17.1 \%$ & $13.9 \%$ & $16.6 \%$ & $9 \%$ \\
\hline Regional & $2.5 \%$ & $5.6 \%$ & $8.3 \%$ & $0 \%$ \\
\hline Local & $27.8 \%$ & $44.4 \%$ & $20.8 \%$ & $31.8 \%$ \\
\hline
\end{tabular}

Cuadro 11: Territorio de la producción cultural (agrupado).

En cuanto al circuito promotor gubernamental, hay que indicar que éste no aparece en las revistas y que cuando aparece en mayor proporción porcentual en los periódicos lo hace al lado del circuito de circulación restringido que necesitan de financiación para su existencia: plástica (museos) y música (sala de conciertos). Sin embargo, la prensa aloja (o aleja) esta información en los lugares menos visibles: noticias breves de la cultura dejadas al margen de la página, pues el centro se reserva para el circuito de circulación extendido o restringido de promoción empresarial, como ya se señalaba.

La administración pública, tanto nacional como distrital, se hace visible cuando se divulgan bienes y servicios culturales que necesitan su financiación. En la muestra no apareció nunca una discusión o información sobre políticas culturales, participación ciudadana, cultura democrática, encuentros ciudadanos o investigaciones financiadas y divulgadas por la administración pública sobre el sector cultural; sólo de manera marginal aparecen convocatorias o premios (0.6\% en El Tiempo y $2.8 \%$ en El Espectador) y de modo excepcional una nota sobre industrias culturales en Colombia en la revista Cambio.

La cultura no es, en las páginas culturales, algo que se construye mediante conflictos y luchas (por presupuestos, significación, representación, definición de políticas, etc.) sino algo a lo que se accede mediante el precio o la financiación. La cultura, nuevamente, es entendida aquí como evento: apacible lugar en el que se encuentran los consumidores.

\section{El lugar de lo popular en las páginas culturales}

No obstante las generalizaciones hechas, es necesario hacer una distinción para El Espectador, que se aparta en muchas variables del resto de la muestra. En primer lugar, hay un espacio destacado para las manifestaciones populares (13.9\%), y una mayor cobertura para asuntos educativos (11.1\%) y convocatorias gubernamentales para la creación y formación (2.8\%). Igualmente es destacable la mayor visibilidad para producción 
local (44.4\%) y que el circuito promotor gubernamental esté representado en un $27.7 \%$ (en $E l$ Tiempo es del $13.9 \%$ y en las revistas no aparece). Finalmente, resulta interesante que en la sección Agenda exista una subsección dedicada a los niños como público, que demuestra un talante incluyente a nivel poblacional no mediado por la rentabilidad económica: la mayor parte de las actividades son gratuitas y de financiación gubernamental. Aquí bien podría decirse que hay una política cultural de iniciativa privada en cuanto a formación de públicos, clave para la consolidación de un mercado de bienes culturales sostenible a lo largo del tiempo.

Mención aparte merecen las creaciones de la cultura popular que no aparecen ni en Cambio ni en Semana y que apenas de modo marginal lo hacen en El Tiempo (2.6\%). Detengámonos en El Tiempo, porque si bien lo popular es marginal alli, también lo es que de una u otra manera aparece. Es necesario preguntarse entonces qué condiciones son necesarias para que lo popular sea representado en este periódico.

El 2.6\% de lo popular corresponde a 4 notas tituladas: "Se trataba de una niña pirata" (1907-04), "Petrona en Suiza" (20-07-04), “Música brasileña en la Blaa" (25-07-06) y "El pacto es con el público" (27-07-04). Veamos el contenido de esas notas.

"Petrona en Suiza. Este jueves, la artista colombiana Petrona Martínez, mejor conocida como 'La Reina del Bullerengue', se presentará en la tercera edición del Paleo Festival, de Nyon (Suiza). Puyas, chalupas, bullerengues y cumbias serán interpretados por Petrona y Sus Tambores, una vez más en el Viejo Continente. Petrona acaba de lanzar su segundo trabajo discográfico, titulado Mi tambolero".

"Música brasileña en la Blaa. Hoy, a las 11 de la mañana, la sala de conciertos de la Biblioteca Luis Ángel Arango recibirá, con el apoyo del Instituto de Cultura Brasil-Colombia, la Embajada de Brasil y Varig, al quinteto brasileño Tira Poeira. La banda, que ha recibido importantes premios en Brasil, interpreta ritmos como el choro, el maxixe y la samba. Calle 11 No. 4-14. Teléfono 3420305."

Se trataba de una "niña pirata" Recojamos parte de la nota: "No estaba destinada a ser un éxito. Rechazada en la grabación y perdida del estudio terminó por imponerse en obra negra ante el público. 'Niña bonita' fue más bien la "niña rechazada" del Binomio de Oro de América, hace cuatro años, cuando Israel Romero la sacó del disco 'Difícil de igualar' para meter otra canción más movida. Después fue la "niña perdida" cuando la pista, más bien una maqueta en obra negra, desapareció de los estudios de Codiscos en Medellín. Ahora es la "niña consentida". Sin estar en algún álbum del Binomio, encabeza las listas de la emisora Radio Uno y ocupa el cuarto lugar en La Vallenata. Sin embargo, su desfile en el top de éxitos lleva meses.

El pacto es con el público, Recojamos parte de la nota: "Los Tigres del Norte recogen en sus canciones el sentir del pueblo mexicano desde hace más de tres décadas (...) La banda, que nació en 1968 de la necesidad de sobrevivir de la familia Hernández (todos los integrantes son familia: hermanos y un primo), más que de la vocación musical, es ahora una institución musical (han vendido 30 millones de discos, compuesto más de 500 canciones). Sus letras tienen eco (sus canciones criticando al ex presidente $\mathrm{Carlos} \mathrm{Sa}-$ linas de Gortari y otra, a Vicente Fox, han sido censuradas). Los intelectuales los buscan (una heroína de sus canciones se convirtió en protagonista de la novela de Arturo Pérez Reverté, $L a$ Reina del sur). Las universidades los invitan a sus encuentros (una fundación que lleva el nombre del grupo, dedicada a la conservación y defensa de la herencia mexicana tiene sede en la Universidad de Ucla, en Los Ángeles) y los exponentes del rock juvenil le rinden homenajes".

Las dos primeras notas aparecen en un apartảdo de la página cultural titulado "Noticias breves de la cultura". Y son, en verdad, breves: en prome- 
dio cada nota de esa sección tiene 64 palabras. Las notas tercera y cuarta ocupan más espacio: media página ( 712 y 750 palabras, respectivamente) que incluyen entrevistas y fotografías de las agrupaciones. Sin embargo, es necesario anotar que aunque agrupemos estas cuatro notas en la noción popular de la cultura debemos proponer algunas distinciones. Como clasificar las dos primeras en lo "popular-folclorizado", manifestaciones culturales que la industria discográfica, de la que hacen parte, ha etiquetado como world music. Las dos últimas se pueden clasificar en lo "popular-masivo" o popular CCE: Los Tigres del Norte han vendido más de 30 millones de discos y en cada gira congregan gran cantidad de público y en el caso de la canción vallenata Niña Bonita, ésta encabeza las listas de la emisora Radio Uno y ocupa el cuarto lugar en La Vallenata, así como varios meses en el top de éxitos musicales.

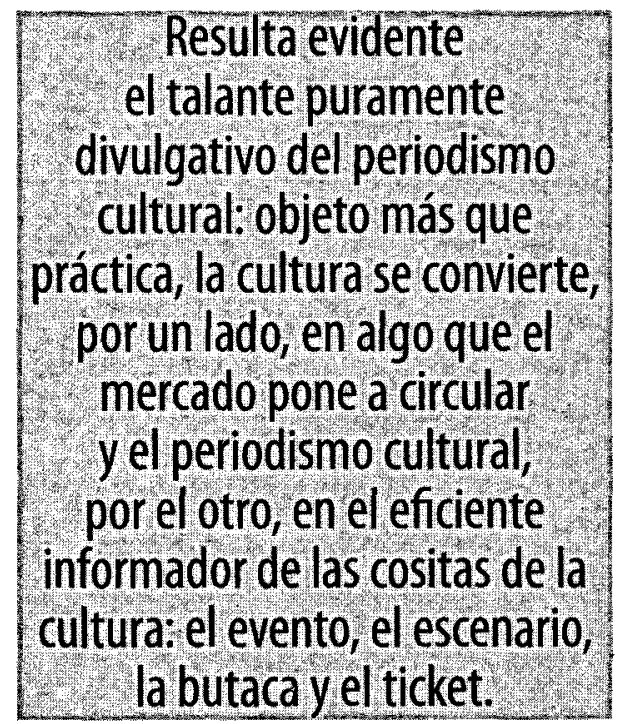

Resulta obvio que el espacio dedicado a las manifestaciones populares es insignificante, pero ¿cuál es el criterio para darle cabida en la página cultural a una manifestación popular?, ¿depende sólo de lo popular o hay "un algo más"? Creemos, en efecto, que es indispensable "un algo más" para que lo popular sea representado en la página cultural de El Tiempo. En el caso de Petrona Martínez, ese "más" depende de la travesía de la artista hecha por Europa, no sólo del bullerengue, sino de la consagración del mismo en el Paleo Festival, de Nyon (Suiza). El bullerengue se legitima, entonces, al otro lado: "una vez más en el Viejo Continente", se señala en la nota. En el caso de "Música brasileña en la Blaa" sucede algo semejante, pues la visibilidad del evento depende en este caso del lugar de su presentación, un sitio consagrado en el ámbito local: la Sala de Conciertos de la Biblioteca Luis Ángel Arango. En cuanto a Los Tigres del Norte y la canción vallenata, la cuestión es diferente, pues su cabida a media página, con foto y entrevista depende de su naturaleza masiva, de su éxito discográfico, del mercado. En este caso es el criterio económico el que media para que lo popular sea representado.

\section{Conclusiones}

En este estudio se buscó mediante un análisis de contenido descubrir qué tipo de representación de la cultura se hace en los periódicos y revistas de circulación nacional. En el transcurso de la investigación se hicieron evidentes otros problemas que inicialmente no se habían planteado. Pues si nuestro punto de partida fue la representación mediática -las páginas culturales-, la indagación empírica se centró en la exploración puramente textual. A partir del texto se hicieron algunas deducciones que apuntaron directo hacia el periodismo cultural, sobre el que no nos habíamos preguntado en el proyecto de investigación y que remitiría a un análisis de tipo más contextual. Si a partir del rastreo textual se descubrió una manera de concebir la cultura en las páginas culturales, construidas bajo el imperativo informativo de la vida buena y de la buena vida, clave en la que se estructuran las llamadas zonas blandas de la prensa -deportes, cocina, sexo, tarot, vida social, salud, espectáculos-, escritas bajo el principio del recetario y el decálogo -"diez pasos para ser un maestro del amor", "Consejos para lograr el risotto perfecto", "Los libros más vendidos del 2005"-, la cultura, ubicada allí, es representada como objeto más que práctica, es decir, como algo que puede, en lo fundamental, producirse, distribuirse y consumirse bajo el precio del mercado o la financiación gubernamental: la cultura entendida como evento (escenario, butaca y ticket).

¿Qué tipo de periodismo cultural es el que se evidencia en esas páginas culturales? Intentando responder esa pregunta a partir de lo puramen- 
te textual se llegó a respuestas poco halagadoras: el periodismo cultural como el oficio de divulgar las cositas de la cultura, como mecanismo clave del mercado de la cultura, particularmente de las industrias culturales: se comenta lo qùe se vende (top ten, best sellers, gran taquilla), eliminando así otras formas de entender la cultura: algo que se construye, por ejemplo, mediante conflictos y luchas (por presupuestos, significación, representación, definición de políticas) y que daría, por tanto, cabida a una concepción más plural de la cultura en las páginas culturales. Según la estrecha relación entre periodismo cultural y economía de la cultura llegamos a considerar que antes que taste makers los periodistas culturales parecen más bien taste workers de catálogo.

Teniendo en cuenta los resultados anteriores son comprensibles las críticas hechas al periodismo cultural. Tanto la crítica docta, que se queja de la falta de "nivel cultural", como la crítica culturalista, que se queja de la falta de "diversidad cultural". La agenda informativa de "la cultura" que proponen los periódicos y revistas de circulación nacional se circunscribe a la noción de evento cultural: creadores y productores que ofertan y clientes que consumen; la cultura entendida como escenario, como butaca y ticket para la buena vida. El periodismo cultural se escribe, en este caso, en clave empresarial: "cuando oigo la palabra cultura, busco la chequera" (según la fórmula de Žižek, 1998). La cultura como proceso de creación colectivo, como algo que constantemente se transforma, como lugar conflictivo y político no aparece allí, pues la cultura es el lugar del cándido encuentro apacible para la vida buena. El periodismo cultural se escribe, en este caso, en clave de precepto: "cuando oigo la palabra revólver, busco la cultura" (Ibíd.). ó

\section{Bibliografía}

BAREI, Silvia (1999). "Periodismo cultural: crítica y escritura". En: Revista Latina de Comunicación Social, número 23, de noviembre de 1999, La Laguna (Tenerife):

http://www.ull.es/publicaciones/latina/ a1999bno/15silvia.htm
ESTENIOU, Javier (1998). "El periodismo cultural en los tiempos de las grandes ciudades". En: Razón y Palabra, no 10, año 3, abril-junio 1998.

FORD, Aníbal; Martini, S. M. y Mazzioti, Nora (1996). "Construcciones de la información en la prensa Árgentina sobre el Tratado del Mercosur". En: Cultura en globalización, N. García Canclini (Ed.), Buenos Aires: Nueva Sociedad.

GARCÍA CANCLINI, Néstor (1990). Cultura hibridas. Estrategias para entrar y salir de la modernidad, México: Grijalbo.

. (2000). "Local, nacional y

global: Cambio de la información cultural en diarios mexicanos", texto presentado en el Encuentro de investigación México-Colombia: Medios, cultura y democracia, Bogotá, 7 al 10 de marzo de 2000.

(2004) Diferentes, desiguales y desconectados. Mapas de la interculturalidad, Barcelona: Gedisa.

MARTÍN BARBERO, Jesús (1991). "Un periodismo para el debate cultural" en $I S e$ minario Internacional de Periodismo Cultural, III Encuentro Nacional de Periodistas Culturales, Bogotá: Tercer Mundo Editores.

Ministerio de Cultura de Colombia (2003). Impacto de las industrias culturales en Colombia, Bogotá: Convenio Andrés Bello.

MORENO-DURÁN, Rafael Humberto (1993). "Sobre televisión y bustos parlantes". En: $P e-$ riodismo cultural y cultura del periodismo, $\mathrm{H}$. Troyano (Ed.), Bogotá: Convenio Andrés Bello.

RIVERA, Jorge (1995). El periodismo cultural, Barcelona: Paidós.

SUNKEL, Guillermo (1985). Razón y pasión en la prensa popular, cultura de masas y cultura política. Santiago: Serie de estudios ILET. . (2004). La prensa sensacionalista y los sectores populares, Bogotá: Norma.

VILLA, María (2000). "Una aproximación teórica al periodismo cultural". En: Revista Latina de Comunicación Social, número 35, de noviembre de 2000, La Laguna (Tenerife): http://www.ull.es/publicaciones/latina/ argentina2000/09villa.htm 
ZAID, Gabriel (2006). "Periodismo cultural" en Elmalpensante, Bogotá: n 69, pp. 19-19. ŽIŽEK, Slavoj (1998). "Multiculturalismo o la lógica del capitalismo multinacional”. En:
Estudios Culturales: Reflexiones sobre el multiculturalismo, E. Grüner (Comp.), Buenos Aires: Paidós, pp. 137-188. 